\title{
Blood-pressure variability in patients with obstructive sleep apnea: current perspectives
}

REVIEW

This article was published in the following Dove Press journal:

Nature and Science of Sleep

\section{Oreste Marrone \\ Maria R Bonsignore ${ }^{1,2}$}

'National Research Council of Italy, Institute of Biomedicine and

Molecular Immunology, ${ }^{2} \mathrm{DiBiMIS}$,

University of Palermo, Palermo, Italy
Correspondence: Oreste Marrone Consiglio Nazionale delle Ricerche, Istituto di Biomedicina e Immunologia Molecolare, I53 Via Ugo La Malfa,

Palermo 90146, Italy

$\mathrm{Tel}+3909 \mid 389$ I36

$\mathrm{Fax}+3909 \mid 6809127$

Email oreste.marrone@ibim.cnr.it
Abstract: Obstructive sleep apnea (OSA) is often associated with hypertension and other cardiovascular diseases. Blood pressure (BP) variability is part of the assessment of cardiovascular risk. In OSA, BP variability has been studied mainly as very short-term (beat-by-beat) and short-term (24-hour BP profile) variability. BP measured on consecutive heartbeats has been demonstrated to be highly variable, due to repeated peaks during sleep, so that an accurate assessment of nocturnal BP levels in OSA may require peculiar methodologies. In 24-hour recordings, BP frequently features a "nondipping" profile, ie, $<10 \%$ fall from day to night, which may increase cardiovascular risk and occurrence of major cardiovascular events in the nocturnal hours. Also, BP tends to show a large "morning BP surge", a still controversial negative prognostic sign. Increased very short-term BP variability, high morning BP, and nondipping BP profile appear related to the severity of OSA. Treatment of OSA slightly reduces mean 24-hour BP levels and nocturnal beat-by-beat BP variability by abolishing nocturnal BP peaks. In some patients OSA treatment turns a nondipping into a dipping BP profile. Treatment of arterial hypertension in OSA usually requires both antihypertensive pharmacological therapy and treatment of apnea. Addressing BP variability could help improve the management of OSA and reduce cardiovascular risk. Possibly, drug administration at an appropriate time would ensure a dipping-BP profile.

Keywords: sleep apnea, ambulatory blood-pressure monitoring, beat-by-beat measurements, blood-pressure dipping, morning blood-pressure surge

\section{Introduction}

Obstructive sleep apnea (OSA) is a well-known cardiovascular risk factor. In patients with OSA, cardiovascular diseases have increased incidence and are associated with worse functional outcomes and increased mortality. ${ }^{1}$ Systemic hypertension, which is often found in OSA, can importantly affect cardiovascular health. Also, altered blood pressure (BP) variability may carry some additional risk for higher incidence and faster progression of cardiovascular disease. ${ }^{2,3}$ Both the degree and pattern of BP variability have prognostic implications. Many methods and calculations have been proposed for assessment of BP variability, but physiological and clinical meanings of each of them are not always clear. ${ }^{4,5}$ In this article, after a brief review of assessment and implications of BP variability in the general population, we focus on BP variability in adult OSA, taking into account methodological, clinical, and therapeutic aspects.

\section{Types of BP variability}

BP variability can be defined as BP fluctuations occurring over time. It can be studied in the very short term (beat to beat), short term ( 24 hours), midterm (day to day), or 
long term (visit to visit). ${ }^{2}$ Whatever the time scale, sympathetic activity is a determinant of BP variability in response to a variety of external and internal stimuli. In the very short term, respiratory influences, postural changes, emotional factors, or environmental conditions are a source of BP changes, while arterial and cardiopulmonary reflexes, arterial compliance, blood viscosity, and humoral factors modulate their amplitude. ${ }^{2}$ Twenty-four-hour BP changes are affected by endocrine influences, genetic factors, degree of diurnal physical and mental activity, and more than anything else by the wake-sleep cycle. ${ }^{6,7}$ In normal subjects, BP decreases when falling asleep, reaches its lowest values and highest stability during slow-wave sleep (SWS), and shows the highest variability during rapid eye movement (REM) sleep. ${ }^{8}$ Midterm and long-term BP variability are representative of BP burden and reflect the degree of control of BP over longer periods. Similarly to very short- and short-term variability, their increase is considered an unfavorable prognostic sign. ${ }^{2}$

Measurement techniques should be appropriately chosen to study each kind of BP variability. Very short-term variability can be studied invasively by means of measurements performed with intra-arterial catheters, or noninvasively by means of a photoplethysmographic sensor applied at a finger using the volume-clamp methodology. ${ }^{9,10}$ In addition, a new noninvasive method to measure beat-to-beat BP at the wrist by applanation tonometry has been recently described. ${ }^{11}$ Twenty-four-hour changes can be detected by BP measurements taken at different times of the day, eg, morning and evening, preferably with home measurements taken by patients themselves (home BP monitoring [HBPM]), or by instruments that automatically measure BP at fixed intervals during the 24 hours (ambulatory BPM [ABPM]). However, HBPM may provide information only on waking BP, whereas BP measurements during sleep can be obtained only with ABPM. For assessment of midterm BP variability, HBPM may be a better choice than ABPM, as ABPM may not be easily tolerated on consecutive days. Patients should preferably use validated automatic devices and receive appropriate training and instructions about the correct modalities to perform the measurements. ${ }^{12}$ Similarly to midterm variability, long-term BP variability may be best monitored by HBPM. Whatever the type of BP assessment to perform, office BP measurements are far from ideal, mainly due to the common "white-coat effect", which can lead to an overestimation of patients' usual BP levels. ${ }^{2}$ Evaluation of mid- and longterm variabilities is particularly useful in the management of hypertensive patients, but very little is known about their behavior in OSA. Therefore, we focus our attention on very short- and short-term variability.

\section{Beat-to-beat BP measurements: very short-term BP variability}

Beat-to-beat BP measurements are ideal to monitor fast changes in autonomic modulation, eg, in awake subjects performing the Valsalva maneuver, which is part of the assessment of patients with autonomic disorders, eg, orthostatic hypotension. ${ }^{13}$ Among the most common applications of beat-to-beat BP recordings is the measurement of cardiac baroreflex sensitivity, which can be assessed both during wakefulness and during sleep. Its evaluation may be useful for prognostic purposes and to assess therapy effectiveness in several diseases, although present knowledge has not yet allowed us to adopt it in clinical routine. ${ }^{14}$ During sleep, beatto-beat measurements reveal sudden BP rises when events disturbing sleep occur, especially when associated with electroencephalography changes (cortical arousals). ${ }^{15}$ BP surges can be a cause of increased nocturnal BP variability, as is usually observed in OSA. In this condition, beat-to-beat BPM may reveal important aspects of BP behavior that would be undetected by any other BP assessment method.

\section{Twenty-four-hour BP: short-term BP variability}

Many types of analyses may be done on 24-hour BP values, including separate measurements of waking and sleeping BP and the 24-hour BP profile. Today, it is commonly agreed that mean BP levels have a higher influence on cardiovascular risk than the 24-hour BP profile. ${ }^{2,16,17}$ In particular, nocturnal BP levels are the most useful predictors of cardiovascular disease. ${ }^{16,18-20}$ Thresholds for normal BP values, assessed by ABPM, have changed over time. Until recently, diurnal values $\geq 135 / 85 \mathrm{mmHg}$ and nocturnal values $\geq 120 / 70 \mathrm{mmHg}$ have been considered representative of diurnal and nocturnal hypertensive BP levels. ${ }^{21}$ According to new guidelines, diurnal values $\geq 130 / 80$ and nocturnal values $\geq 110 / 65 \mathrm{mmHg}$ should be considered hypertensive. ${ }^{12}$

However, some types of circadian BP changes also carry an independent risk, and the evaluation of the circadian BP profile helps to understand mechanisms governing BP changes better and establish more appropriate therapy in each hypertensive subject. In normal subjects, BP usually exhibits one peak early in the morning and one peak late in the afternoon or early evening. ${ }^{6,7}$ Either higher morning or evening BP have been reported, as some studies, mainly in 
Asian subjects, found higher values in the morning, while other studies, mainly in European subjects, in the evening. ${ }^{22}$ It has been claimed that morning BP better predicts cardiovascular risk than evening $\mathrm{BP},{ }^{23}$ particularly when the morning:evening BP ratio increases. ${ }^{24}$

The 24-hour BP profile is evaluated mainly as change in mean BP from day to night. Since sleep is a major determinant of the diurnal change, usually causing a decrease in BP, BP measurements taken during waking and sleeping should be considered separately. For the sake of simplicity, fixed time ranges relevant to estimated waking and sleeping time are often used. They can be set as wide-fixed or narrow-fixed intervals. With the first method, all 24-hour measurements are taken into account and subdivided into waking and sleeping values. According to the other method, periods estimated as transition times between waking and sleeping are discarded. ${ }^{25}$ Ideally, waking and sleeping measurements should be estimated individually based on sleep diaries or (better) on results of monitoring by instruments helping to define waking and sleeping times, like actigraphs. ${ }^{26}$

Although definitions may vary, ${ }^{19}$ the following BP 24-hour profiles are commonly considered: "dipping", mean nocturnal reduction in BP by $10 \%-20 \%$; "nondipping", nocturnal reduction in BP between 0 and 10\%; "reverse dipping" or "riser" pattern, increase in mean BP during the night; "extreme dipping", nocturnal reduction in BP $>20 \%$. While the dipping pattern is considered physiological and associated with the lowest risk, nondipping and extreme-dipping patterns carry an intermediate risk and the reverse-dipping profile carries the highest risk of cardiovascular events. ${ }^{27}$

Another way to look at the 24-hour BP variability is to compare nocturnal and morning BP to measure the "morning BP surge" (MBPS). BP normally increases after morning awakening. ${ }^{6}$ An increase in cardiac output in young subjects and increased arterial stiffness in the elderly play a role in determining MBPS. ${ }^{28}$ Elderly subjects usually have higher MBPS compared to young subjects. The definition of a normal MBPS rise is lacking, but a J- or U-shaped relationship between the degree of MBPS and cardiovascular risk has been proposed. ${ }^{28}$

MBPS can be calculated following different criteria (Figure 1). The most commonly used are: sleep-trough morning surge, defined as the difference between the average BP over 2 hours after waking and the average of three consecutive $\mathrm{BP}$ recordings, centered on the lowest reading during sleep; and the prewaking morning surge, defined as the difference between the average BP recordings 2 hours after waking and average BP recordings over 2 hours before waking up. ${ }^{28,29}$ The MBPS has been proposed as a potential contributor to the increased incidence of cardiovascular events in the morning hours. However, while some authors have confirmed the importance of the MBPS as a cardiovascular risk factor, ${ }^{29-31}$ others have reported opposite findings, with less risk in subjects with elevated MBPS. ${ }^{32-34}$

An apparently obvious objection raised to the MBPS concept is that subjects with high MBPS may actually show low

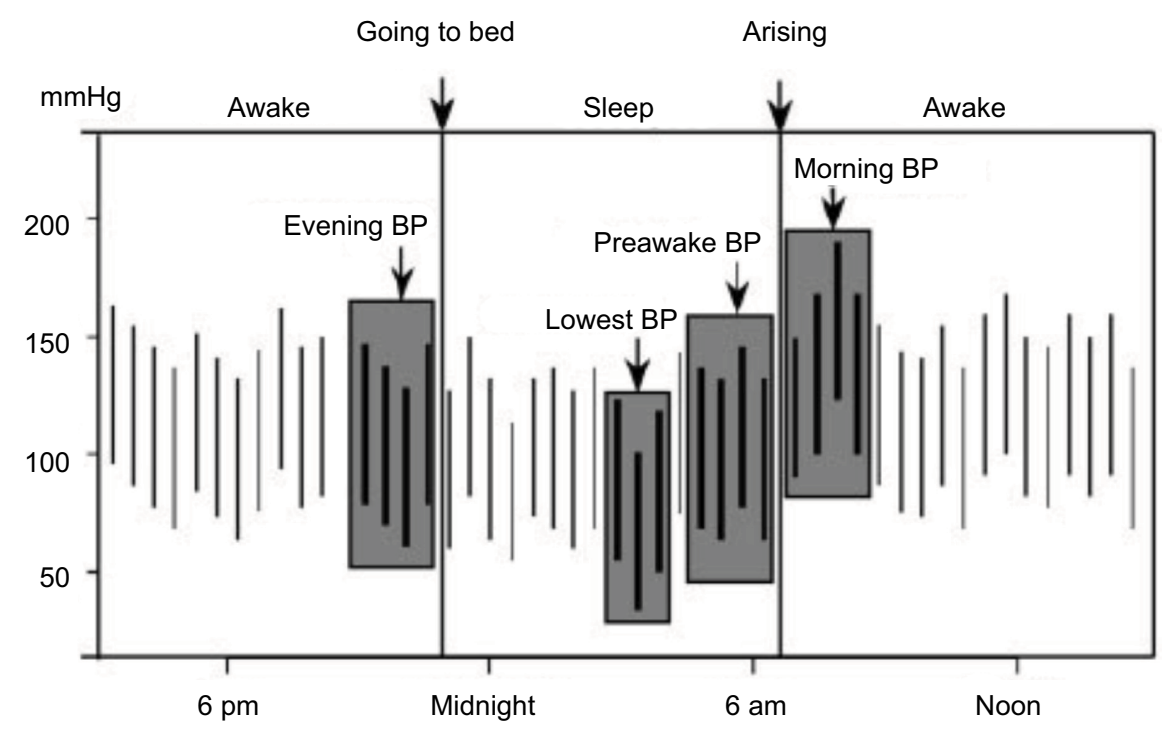

Figure I Measurements of morning blood pressure surge (MBPS).

Notes: Sleep-trough MBPS definition: mean blood pressure in the 2 hours following morning awakening - lowest nocturnal blood pressure (measured as the mean of three measurements centered on the lowest nocturnal value). Prewaking MBPS definition: mean blood pressure in the 2 hours following morning awakening - mean blood pressure in the 2 hours preceding morning awakening. Copyright @2003. American Heart Association, Inc. Reproduced from Kario K, Pickering TG, Umeda Y, et al. Morning surge in blood pressure as a predictor of silent and clinical cerebrovascular disease in elderly hypertensives: a prospective study. Circulation. 2003; 07 (I0): I40 I-I406 (https://www. ahajournals.org/doi//0.1 I6I/0I.cir.0000056521.67546.aa). ${ }^{29}$ 
nocturnal BP levels, which is difficult to reconcile with the well-known risk represented by nocturnal hypertension. Along the same lines, a high MBPS may be the effect of extreme dipping, such that it could be associated with increased cardiovascular risk due to very low nocturnal BP and not to high morning BP. Although an elevated MBPS is more common among extreme dippers, only a fraction of them have a high MBPS. According to one study, only $24 \%$ of extreme dippers have a high MBPS. Also, when extreme dipping and high MBPS coexist, increased cardiovascular risk appears to be associated more with the morning BP rise than with excessively low nocturnal BP. ${ }^{29}$ Finally, a high MBPS, assessed by sleep-trough morning surge, may be associated with nocturnal hypertension in subjects who show a progressive increase in BP from the beginning to the end of the night (Figure 2). ${ }^{35}$

In clinical practice, ABPM is typically used in specialized hypertension clinics, especially for patients who have resistant or refractory hypertension. However, the importance and usefulness of ABPM measurements should lead to it being used clinically more often than it is at present.

\section{BP variability in OSA}

Patients with OSA are characterized by a high prevalence of arterial hypertension, which may exceed $50 \%,{ }^{36}$ and by high $\mathrm{BP}$ variability. In fact, OSA is frequently associated with factors, often interrelated, with important influences on the cardiocirculatory system, like oxidative stress, inflammation, endothelial dysfunction, and high sympathetic tone, ${ }^{1}$ which increase during sleep as an immediate effect of respiratory disorders and remain high during wakefulness. ${ }^{37}$ These factors may increase BP levels and variability chronically.
The greatest peculiarities in BP behavior in OSA are seen during sleep. Pulsus paradoxus, ie, inspiratory reduction in BP $\geq 10 \mathrm{mmHg}$, occurs in obstructed breaths with strong respiratory efforts. ${ }^{38,39}$ More importantly, obstructive apnea termination is characterized by a BP peak lasting only a few seconds that is followed by a return of BP to or below baseline. ${ }^{40}$ Therefore, the higher the number of apneas during sleep, the higher the number of BP oscillations. However, the amplitude of BP peaks is highly variable in relationship to sympathetic reactivity, which in turn is related to end-apneic hypoxemia, occurrence and strength of arousals at the end of each event, age of patients, and normotensive/hypertensive state. ${ }^{41-43}$ The rate and amplitude of BP peaks during sleep are fundamental determinants of the degree of variability of BP during the night and of the mean change in BP from day to night. Apneic events are less frequent in SWS, ${ }^{44}$ and are usually longer and associated with worse hypoxemia in REM sleep. ${ }^{45}$ Therefore, the respective duration of the various sleep stages may also influence nocturnal BP behavior in OSA through rate and severity of events in each of them. Due to the numerous, large, and rapid changes in BP during the night, information on BP in OSA is heavily affected by the method used for its assessment. Optimal detection of different parameters describing BP levels or variability may take advantage of different monitoring techniques.

\section{Role of frequent diurnal and nocturnal BP measurements: very short-term variability} Continuous BP monitoring is not easily tolerated for prolonged periods of time, and may give rise to frequent artifacts,

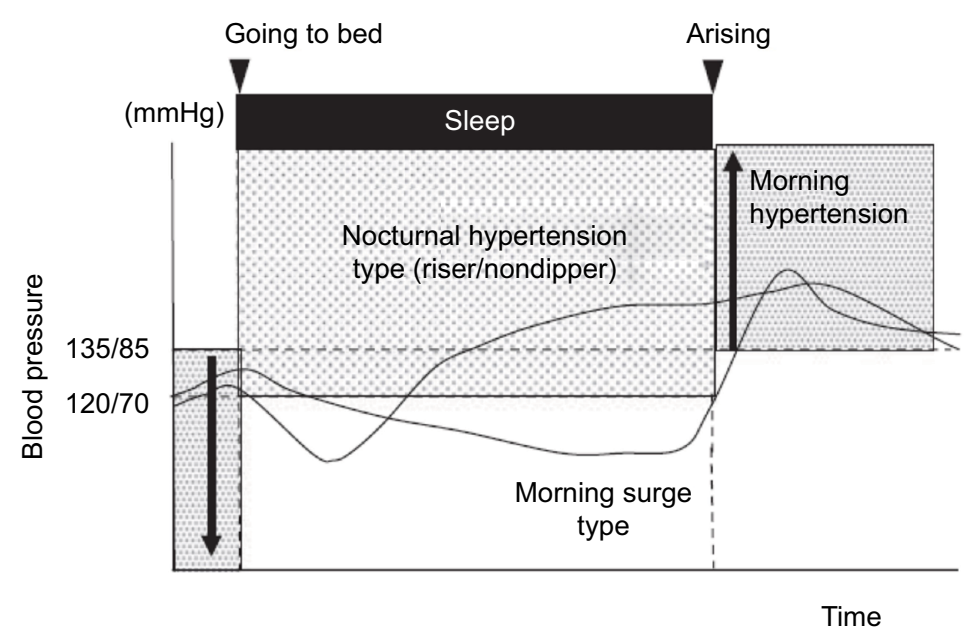

Figure 2 Different blood-pressure profiles in two subjects with high sleep-trough morning blood pressure surge (MBPS).

Notes: High MBPS may or may not be associated with low nocturnal blood pressure. Copyright @2005. American Journal of Hypertension, Ltd. Reproduced from Kario K. Time for focus on morning hypertension: pitfall of current antihypertensive medication. Am J Hypertens. 2005; I8(2 Pt I): I49-I5I, by permission of Oxford University Press. ${ }^{35}$ 
eg, due to limb movements. Therefore, beat-by-beat BP measurements are often performed during short representative time lapses. When recorded during wakefulness, their analysis is not more useful in OSA than in normal subjects, whereas they provide valuable and unique information on BP behavior in sleeping OSA subjects.

Intra-arterial measurements were already obtained in very early studies in OSA patients, and revealed the rapid oscillations associated with apneic events ${ }^{40}$ that were later confirmed with the use of noninvasive techniques. . $^{41,43,46-50}$ Beat-by-beat evaluation of BP showed that during sleep, compared to the immediately preceding quiet wakefulness, mean BP falls if breathing is unobstructed, while it changes little during nonapneic snoring. ${ }^{47}$ Conversely, in OSA, mean BP during sleep can be higher than during quiet wakefulness, with a trend to highest values during REM sleep. ${ }^{46,51}$

The advantage of beat-by-beat BP measurements in OSA is that they provide accurate information about very short-term variability in BP, although they are less accurate in the assessment of absolute BP values. During wakefulness, beat-by-beat measurements show increased variance in BP proportional to the severity of OSA. ${ }^{52}$ Progression from quiet waking to non-REM to REM sleep is associated with an increasing coefficient of variation in BP values. ${ }^{46}$ The SD of BP values during sleep is higher in OSA than in non-OSA subjects, although in both groups BP variability is similarly modulated by sleep stage, being lowest during SWS. Frequency of arousals and respiratory events are correlated with systolic and diastolic BP SD, although they do not fully explain them. ${ }^{49}$

We used beat-by-beat BP measurements to compare accuracy of different sampling rates in the assessment of mean nocturnal BP in subjects with severe OSA and in non-OSA controls. In each subject, mean systolic and diastolic BP were calculated, averaging measurements taken on all heartbeats of one night. Then, mean BP values of the same night were measured, averaging values of heartbeats sampled each $5,10,15$, 20 and 30 minutes. The mean values obtained from heartbeats sampled at each rate were compared to values calculated on all heartbeats. At all sampling intervals in both patients and controls, mean differences between mean systolic and diastolic nocturnal BP values calculated on sampled and all-night heartbeats were small, but the scatter of the differences was higher in the OSA group, especially when long sampling intervals were used (Figure 3). In the OSA subjects, a sampling rate about three times that in the non-OSA subjects was necessary for a similarly accurate assessment of mean nocturnal BP. ${ }^{53}$

It has been claimed that cuff inflations for ABPM measurements can cause arousals, transiently increasing BP, so
A

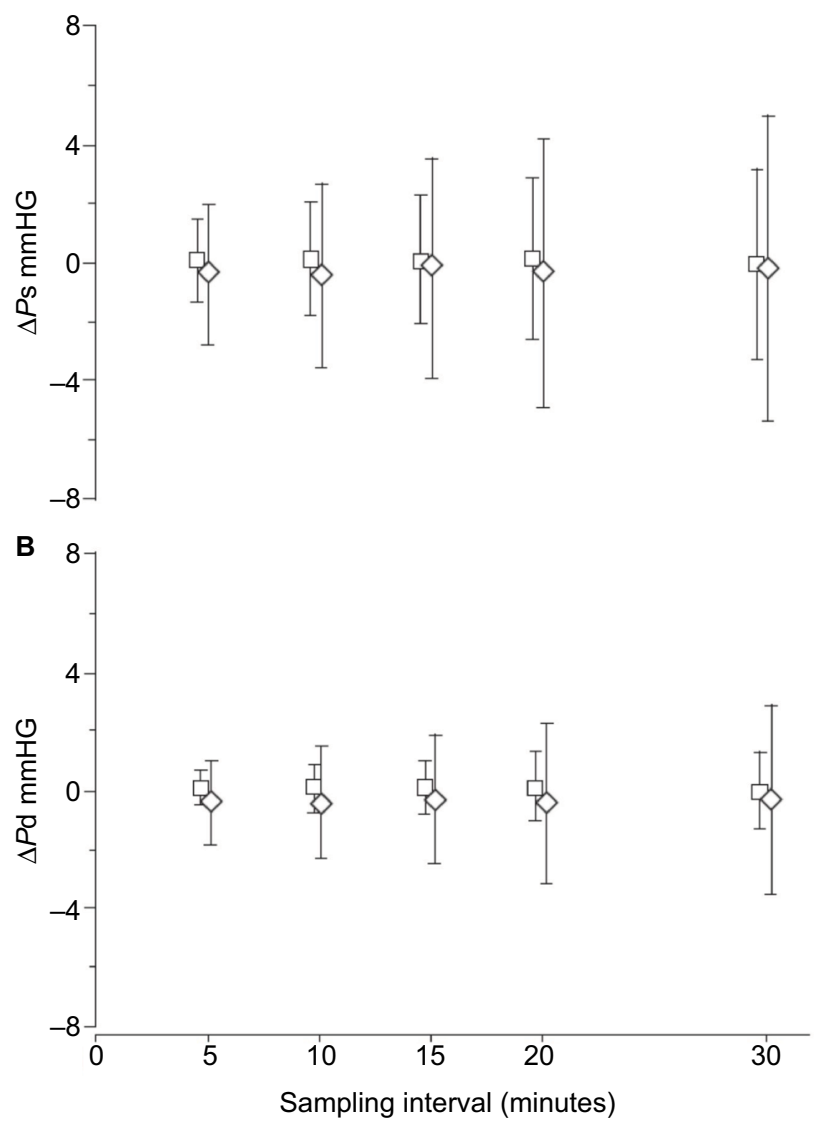

Figure 3 Means \pm SD of $(\mathbf{A}) \Delta P$ s and (B) $\Delta P$ d values in control $(\square)$ and obstructive sleep apnea $(\diamond)$ subjects for each sampling interval.

Notes: $\Delta \mathrm{Ps}$ and $\Delta \mathrm{Pd}$ : differences in $\mathrm{mmHg}$ between the mean nocturnal blood pressure values, respectively systolic and diastolic, obtained from sampled single heart beats and from all heart beats. Copyright (C2000. ERS Journals Ltd. Reproduced from Marrone O, Romano S, Insalaco G, Bonsignore MR, Salvaggio A, Bonsignore $G$. Influence of sampling interval on the evaluation of nocturnal blood pressure in subjects with and without obstructive sleep apnoea. Eur Respir J. 2000; 16(4):653-658..$^{53}$

that BP levels detected by ABPM are higher than during undisturbed sleep. ${ }^{54}$ In OSA subjects, this result proved true for systolic pressure, which is measured soon after brachial cuff inflation, but not for diastolic pressure, which is measured later so that it is less affected by the arousal. ${ }^{55}$ Our experience with five sleepy patients with severe OSA was that the time taken by ABPM to perform each measurement was usually longer than an apneic cycle, ie, an apnea and the following ventilation interval, and rarely caused arousals prematurely interrupting the apnea occurring during the measurement (Figure 4).$^{53}$ Therefore, frequent BP measurements by ABPM may not significantly disturb sleep and BP behavior in severe OSA patients.

Whatever the time between measurements obtained at fixed intervals, ABPM may hardly be able to reveal extreme BP levels, which are often (but only transiently) reached in 


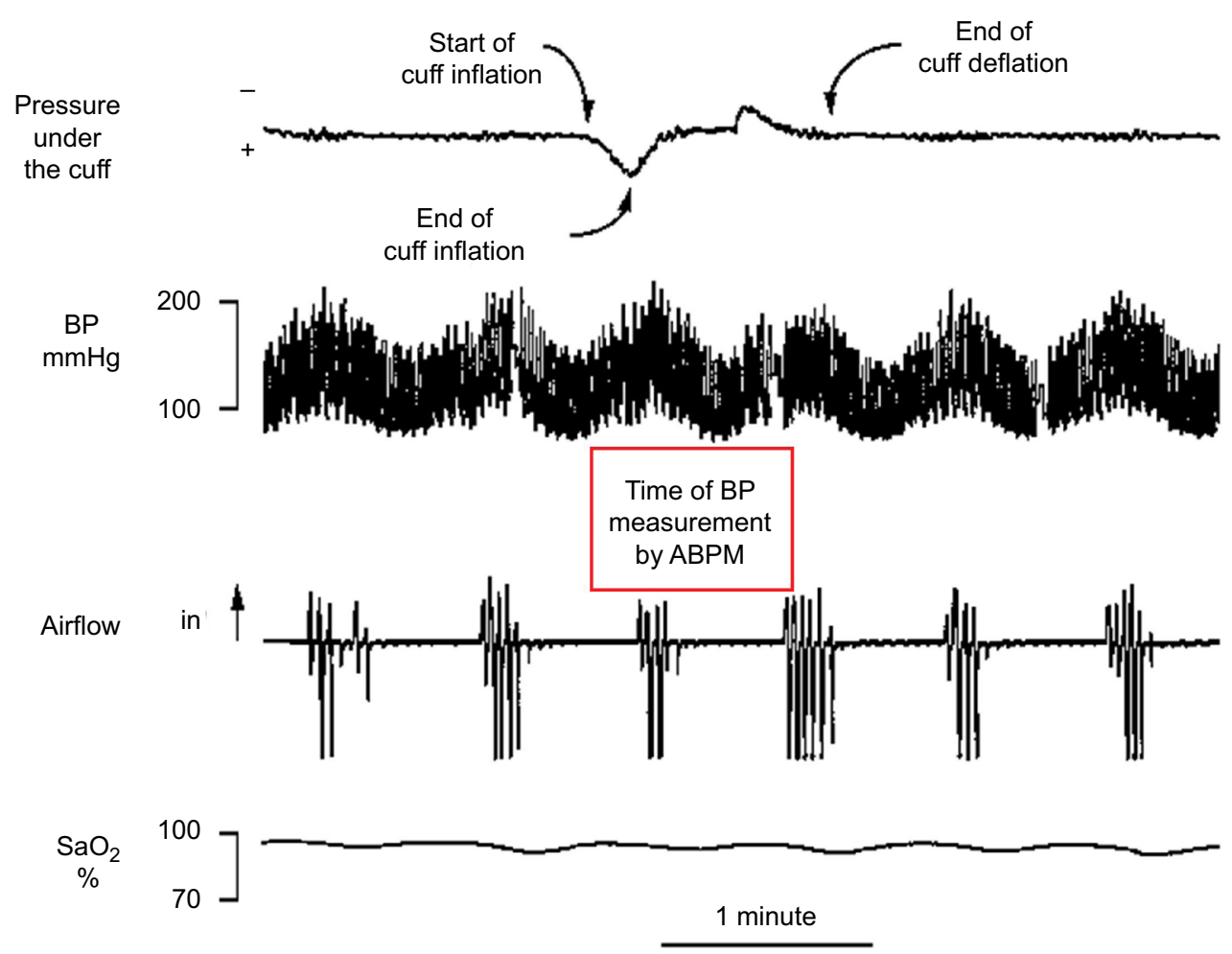

Figure 4 Fragment of a polygraph recording in a representative sleepy patient with severe obstructive sleep apnea.

Notes: Patient undergoing simultaneous continuous finger blood pressure monitoring and ambulatory blood pressure monitoring (ABPM). Top to bottom: pressure detected by an open hose placed under the cuff for ABPM measurements; beat-by-beat blood pressure (BP); nasal airflow; oxyhemoglobin saturation (SaO ${ }_{2}$ ). A flat airflow signal identifies apnea time. In this patient, apnea duration was similar before and during ABPM measurement, which indicates that the cuff inflation did not cause any arousal shortening habitual apnea duration. ABPM measurement required a time exceeding the duration of an apnea cycle, ie, of an apnea and following ventilation. During that period, $B P$ values largely varied, but only one systolic and one diastolic value were obtained by ABPM.

OSA at night. To overcome this problem, a nocturnal BPM method triggered by occurrence of oxygen desaturation has been developed. ${ }^{56}$ This method shows a fair degree of reproducibility, ${ }^{57}$ but the time required for a measurement and the short duration of the BP rise may reduce the accuracy of detection of BP peaks. However, it represents a clear advancement in the assessment of nocturnal BP in OSA with respect to ABPM.

\section{Twenty-four-hour BP profile: short-term BP variability}

Some information about the diurnal BP changes in OSA has been obtained with measurements taken in the evening and the next morning, after awakening. According to this methodology, the morning BP levels in OSA tend to exceed the evening ones. Most studies have reported that the eveningto-morning BP difference was correlated with OSA severity (Table 1). ${ }^{48,58-64}$

A large number of studies have been based on ABPM, with nocturnal BP measurements taken every 15 , 20, or 30 minutes. Surprisingly, the first ABPM studies did not demonstrate increased nocturnal BP in OSA. ${ }^{65,66}$ Rather, one underscored the occurrence of large drops in BP in some subjects with mildly elevated apnea/hypopnea index (AHI) values, but large oxygen saturation falls. This observation remained isolated and unexplained. However, recruited patients were old, and increased arterial stiffness could be responsible for high diurnal $\mathrm{BP}$ values and blunted $\mathrm{BP}$ reactivity to sleep-respiratory disorders and arousals. ${ }^{65}$ Instead, most of the following studies reported that patients with OSA showed a nondipping more commonly than a dipping BP pattern. ${ }^{67-72}$

In OSA, use of ABPM has also proved useful in highlighting high prevalence of masked hypertension, ie, normal office BP values with high mean values at the ABPM assessment. Masked hypertension in OSA could be a consequence of mean nocturnal BP exceeding normal levels. ${ }^{73}$ However, two studies found that it could frequently also be due to high diurnal BP values detected only by ABPM. ${ }^{74,75}$

Other studies extended analysis of ABPM recordings beyond mean diurnal and nocturnal BP (Table 2) ${ }^{76-79}$ Altogether, OSA, and especially severe OSA, was associated 
Table I Studies based on morning and evening BP measurements

\begin{tabular}{|c|c|c|}
\hline Authors & Subjects under study & Findings \\
\hline Hoffstein and & 611 suspected OSA & If $\mathrm{AHI}<10$ : BP morning < BP evening \\
\hline \multirow[t]{2}{*}{ Mateika $^{58}$} & & If $\mathrm{AHI}$ I0- $\leq 50$ : $\mathrm{BP}$ morning $=\mathrm{BP}$ evening \\
\hline & & If $\mathrm{AHI}>50$ : $\mathrm{BP}$ morning $>\mathrm{BP}$ evening \\
\hline Sforza and & 253 suspected OSA & In both simple snorers and OSA: BP morning > BP evening \\
\hline 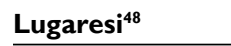 & & $\mathrm{SBP}$ evening-to-morning rise correlated to $\mathrm{AHI}$ \\
\hline Stradling et $\mathbf{a}^{59}$ & $\begin{array}{l}448 \text { subjects from general } \\
\text { population }\end{array}$ & $\begin{array}{l}\mathrm{ODI}_{4} \text { and mean nocturnal respiratory effort independently correlated with evening-to-morning } \\
\mathrm{BP} \text { rise }\end{array}$ \\
\hline $\begin{array}{l}\text { Lavie-Nevo and } \\
\text { Pillar }\end{array}$ & 2,009 suspected OSA & SBP and DBP evening-to-morning rise correlated with $\mathrm{AHI}$ in men, but not in women \\
\hline Ting et $\mathbf{a l}^{63}$ & $\begin{array}{l}263 \text { simple snorers, UARS } \\
\text { or OSA }\end{array}$ & $\begin{array}{l}\text { Subjects with morning:evening } \mathrm{BP} \text { ratio }>\mathrm{II} \% \text { ("morning surge" pattern) or with mean both } \\
\text { morning and evening } \mathrm{BP}>130 \mathrm{mmHg} \text { ("constant high") had higher } \mathrm{AHI} \text {, lower lowest } \mathrm{SaO}_{2} \text {, } \\
\text { longer } \mathrm{T}<90 \% \text { and higher arousal index than subjects with morning:evening } \mathrm{BP} \text { ratio }<1 \mathrm{I} \% \\
\text { ("morning drop") or both morning and evening mean } \mathrm{BP}<130 \mathrm{mmHg} \text { ("constant low"); similar } \\
\text { percentage of sleep stages in all groups }\end{array}$ \\
\hline Huang et $\mathbf{a l}^{64}$ & $\begin{array}{l}105 \text { positional and } 266 \text { non- } \\
\text { positional OSA }\end{array}$ & $\begin{array}{l}\text { Morning BP higher in nonpositional OSA; evening BP and evening-to-morning BP difference } \\
\text { similar in positional and nonpositional OSA }\end{array}$ \\
\hline Wang et $\mathbf{a l}^{60}$ & 3246 OSA + 354 controls & Progressive increase in morning/evening mean BP with increasing OSA severity \\
\hline Mokros et al ${ }^{62}$ & $\begin{array}{l}454 \text { normotensive } \\
\text { suspected OSA }\end{array}$ & AHI linearly correlated with evening-to-morning DBP rise, but not SBP rise \\
\hline
\end{tabular}

Note: Arousal index, number of arousals per hour; $\mathrm{ODI}_{4}$, number of oxyhemoglobin saturation falls $\geq 4 \%$ per hour.

Abbreviations: $\mathrm{AHI}$, apnea/hypopnea index; BP, blood pressure; DBP, diastolic BP; ODI, oxygen desaturation index; OSA, obstructive sleep apnea; SaO ${ }_{2}$, oxyhemoglobin saturation; SBP, systolic BP; T<90\%, time spent with oxyhemoglobin saturation $<90 \%$; UARS, upper airway resistance syndrome.

Table 2 24-Hour BP characteristics in obstructive sleep apnea: beyond dipping and nondipping

\begin{tabular}{|c|c|c|}
\hline Authors & Subjects under study & Profiles \\
\hline \multirow[t]{3}{*}{ Noda et al ${ }^{76}$} & 21 OSA + 123 non-OSA & Type I: normal BP throughout the 24-hour period with nocturnal BP fall (OSA + non-OSA) \\
\hline & & Type 2: progressive BP elevation from onset of sleep to early morning (hypertensive OSA) \\
\hline & & Type 3: elevated BP at any time (hypertensive OSA) \\
\hline \multirow[t]{4}{*}{ Nagata et al ${ }^{77}$} & 5 non-OSA, 10 mild OSA, & Nocturnal BP: moderate and severe OSA > non OSA \\
\hline & 12 moderate OSA, 27 & Morning BP: severe OSA > non OSA \\
\hline & severe OSA & Nocturnal BP fall: severe OSA $<$ non OSA \\
\hline & & Diurnal and evening BP: OSA $=$ non OSA \\
\hline \multirow[t]{4}{*}{ Sasaki et a ${ }^{78}$} & 103 OSA & $\begin{array}{l}\text { Sustained type: both diurnal and nocturnal hypertension; profile related to OSA severity and sleep } \\
\text { disruption }\end{array}$ \\
\hline & & Surge type: only morning hypertension; profile related to reduced SWS \\
\hline & & Control type: neither diurnal nor nocturnal hypertension \\
\hline & & Nocturnal hypertension only: not analyzed, few patients \\
\hline Cho et $\mathrm{al}^{79}$ & $\begin{array}{l}\text { Hypertensives, } 35 \text { OSA + } \\
23 \text { non-OSA }\end{array}$ & Sleep-trough morning SBP surge: OSA > non-OSA \\
\hline
\end{tabular}

Abbreviations: BP, blood pressure; OSA, obstructive sleep apnea; SBP, systolic BP; SWS, slow-wave sleep.

not only with increased nocturnal but also with increased morning BP. Differences in diurnal and evening BP observed between subjects with and without OSA were milder, confirming the results obtained with waking evening and morning measurements described earlier.

Factors associated with high BP levels and nondipping profile observed at ABPM have been investigated in several cross-sectional studies. Significant relationships between increased AHI or oxygen desaturation index (number of oxygen saturation dips per hour of sleep) and reduced nocturnal BP dipping have been found in community and OSA populations..$^{59,68,69,80}$ Other studies on OSA, while confirming a role of nocturnal hypoxemia, stressed the importance of arousals as possible determinants of nocturnal BP and 24-hour BP profile. ${ }^{76,81}$ By contrast, another study could not demonstrate differences between dippers and nondippers in the rate of arousals or SWS duration. ${ }^{71}$ Differences between studies could be at least partially accounted for by variable relationships of the nondipping phenomenon in different subjects. In fact, according to some authors, in young OSA patients nondipping was correlated with the severity of respiratory disorders, and in elderly patients with reduced SWS and REM and increased stage 1 duration. ${ }^{82}$ In a subsequent study, the same authors demonstrated that 
while a sustained high BP profile was associated with both OSA severity and altered sleep architecture, the MBPS was associated only with altered sleep architecture. ${ }^{78}$ Morning BP was the object of another study that found that the severity of sleep-respiratory disorders in hypertensive subjects, though not directly affecting morning BP, was independently correlated with the MBPS. ${ }^{83}$

Two longitudinal studies evaluated the incidence of a nondipping BP pattern in relationship to OSA in a general population cohort (the Wisconsin Sleep Cohort). In the first, an independent relationship between AHI values and incidence of systolic nondipping was demonstrated. ${ }^{84}$ In the second, the risk of developing systolic and diastolic nondipping was significantly correlated with AHI values in REM, but not in non-REM sleep. ${ }^{85}$

In summary, cross-sectional studies have shown that high-severity sleep-respiratory disorders and altered sleep architecture may be related to increased BP, especially at night, and to reduced nocturnal BP dipping, but data were inconsistent, possibly due to numerous confounding factors. Longitudinal studies, coming from only one cohort, support a role of sleep-respiratory disorders, especially if occurring during REM sleep, as determinants of nondipping BP.

\section{Other measurements of BP variability}

Besides the BP pattern over 24 hours, the SD of the measurements taken with ABPM has been commonly used as a parameter of variability. ${ }^{68,74,86-91}$ Other parameters have been coefficient of variation, ${ }^{89}$ average real variability (ie, average of absolute differences between consecutive measurements), ${ }^{89}$ time rate index (ie, rate of change of BP over time, defined as the first derivative values of BP by time) ${ }^{87}$ Heterogeneous studies designs were evident. Two studies compared subjects with and without OSA, ${ }^{87,88}$ two compared hypertensive subjects with and without OSA, ${ }^{89,90}$ one compared subjects with mild-moderate and severe OSA, ${ }^{91}$ one evaluated patients with moderate-severe OSA before and after continuous positive airway pressure (CPAP) treatment, ${ }^{86}$ and one evaluated OSA subjects with normotension, established hypertension, or masked hypertension. ${ }^{74}$ Therefore, results of these studies are hard to compare. Some relationship between OSA and BP variability was observed in most of them. However, depending on the study, an effect of OSA was variably apparent on systolic or diastolic BP or on 24-hour, diurnal, or nocturnal BP. We believe that ABPM may roughly catch BP variability in the nocturnal hours in OSA for the reasons explained, which could account for some disagreement among studies. Little information is available on mid- and long-term $\mathrm{BP}$ variability in OSA. No effect on morning-to-morning BP was reported during CPAP withdrawal for 2 weeks, which suggested that OSA does not significantly influence midterm BP variability. ${ }^{92}$

\section{Twenty-four-hour BP profile and cardiovascular risk}

The characteristics of BP variability in OSA likely contribute to cardiovascular risk and to a peculiar temporal pattern of occurrence of cardiovascular events. Little direct evidence is available of a relationship between BP profile and cardiovascular risk in OSA. Among OSA patients studied with repeated morning and evening $\mathrm{BP}$ measurements, those with an MBPS showed higher high-sensitivity C-reactive protein levels. ${ }^{61}$ Similarly, among OSA patients studied by ABPM, nondippers showed higher levels of IL2 and high-sensitivity C-reactive protein than dippers. ${ }^{93,94}$ Patients with both moderate-severe OSA and reverse-dipping BP profile showed worse brain white matter lesions than subjects with one condition alone..$^{95}$ In a retrospective study, it was observed that OSA patients who had shown a nondipping-BP profile had a higher incidence of stroke, coronary artery disease, and heart failure in a 43 -month period. ${ }^{96}$

A support to the role of the BP profile is also given by indirect evidence. While in the general population major cardiovascular events and sudden death occur preferentially in the morning hours, ${ }^{6}$ in OSA their distribution in the 24-hour period seems to be different. Among subjects who had been studied by polysomnography and died from sudden cardiac death, the fatal events had a peak during the night if OSA had been diagnosed, and a nocturnal nadir in non-OSA subjects. ${ }^{97}$ According to a recent larger investigation, sudden cardiac deaths were evenly distributed in the 24 hours in OSA patients, whereas non-OSA subjects died preferentially in the morning. ${ }^{98}$ Two studies pointed out that in OSA patients, the onset of acute coronary syndrome was more frequent in the nocturnal hours, differently from subjects without OSA. ${ }^{99,100}$ In addition, a few studies showed that wakeup strokes were strongly associated with OSA. ${ }^{101,102}$ Multiple factors may be responsible for triggering cardiovascular events at night, but it is likely that the altered BP profile plays an important role. All these findings indicate that risk associated with OSA increases especially at night and not in the morning. Therefore, in OSA nocturnal hypertension and a nondipping or reverse-dipping pattern might influence cardiovascular risk more than MBPS. 


\section{OSA treatment and BP variability}

In the management of OSA, the main focus is usually on the elimination of respiratory disorders during sleep. Treatment of OSA can reduce many symptoms and risk factors, usually to an extent that is proportional to the correction of the respiratory disorders. ${ }^{103}$ It would also be important to reduce cardiovascular risk factors, including abnormal BP during sleep. For a long time, treatment of hypertensive patients has been aimed almost exclusively at maintaining normal BP levels, not rarely measured just as office diurnal $\mathrm{BP}$ values, which are often misleading. More recently, BP variability, including the 24-hour profile of BP, has been brought to the attention of clinicians as a possible target of treatment. A chronotherapy of hypertension, aimed at more carefully controlling nocturnal BP levels and converting a nondipping into a dipping $\mathrm{BP}$ profile, has been proposed as a convenient treatment strategy. ${ }^{104}$

In OSA, antihypertensive drugs may reduce BP levels, but have at most a limited effect, if any, on sleep-respiratory disorders, such that they cannot substantially reduce nocturnal BP variability. Instead, elimination of respiratory disorders during sleep may be expected to prevent BP peaks and to reduce variability in BP during the night. Meta-analyses have consistently shown that on average, OSA treatment reduces BP by a small amount, with somewhat larger reduction in nocturnal levels. ${ }^{105-108}$ Effects are more evident in patients with severe OSA and with high compliance with treatment. ${ }^{105,107}$ CPAP treatment and pharmacological therapies have additive effects on $\mathrm{BP},{ }^{109,110}$ so the best strategy to treat hypertension and improve characteristics of BP variability in OSA usually includes both kinds of therapy.

A timely administration of antihypertensive drugs might reduce nocturnal BP and restore normal dipping, but few data are available on chronotherapy for altered BP in OSA. A crossover study demonstrated that when antihypertensive therapy was administered in the evening, nifedipine was more effective than carvedilol in decreasing mean and minimum nocturnal systolic BP, but only carvedilol decreased sleep BP peak. ${ }^{111} \mathrm{~A}$ similar decrease in nocturnal BP peak was observed in a patient with evening administration of doxazosin. ${ }^{12} \mathrm{~A}$ crossover study demonstrated that evening administration of valsartan, associated or not with amlodipine, was more effective than morning administration in reducing nocturnal $\mathrm{BP}$ and converting a nondipping into a dipping BP profile. ${ }^{113}$ Instead, no advantage was found with evening compared to morning administration of perindopril in a randomized controlled trial conducted on hypertensive OSA patients. ${ }^{10}$
Several studies, largely differing in design and objectives, have investigated effects of CPAP on BP variability (Table 3 ). One group of studies evaluated nocturnal BP by means of beat-by-beat measurements. They demonstrated that BP variability during sleep acutely decreased while CPAP was applied, ${ }^{39,46,114}$ which is a consequence of a reduction in the number of BP peaks. ${ }^{115}$ Furthermore, beat-by-beat BP variability before CPAP initiation was higher than immediately after CPAP withdrawal, following an approximately 5-month treatment period, ${ }^{116}$ in agreement with the observation of lower postapneic BP peaks at CPAP withdrawal. ${ }^{50} \mathrm{~A}$ second group of studies used ABPM and analyzed the change in 24-hour BP variability. ${ }^{67,70,117-123}$ The period of observation ranged between 1 day and 3 months, depending on the study. In all cases, some of the patients who were nondippers before CPAP initiation were found to be dippers after treatment, but the proportion of patients showing this change largely differed among studies. No effect of $\leq 1$-week CPAP treatment on BP measurement SD during the day or night was reported.$^{86}$ Finally, a group of investigations evaluated BP variability with office or home BP measurements, and found some effect of CPAP treatment on waking systolic BP variability. ${ }^{92,124}$ In summary, CPAP treatment acutely decreases nocturnal very short-term BP variability. A few weeks of CPAP treatment may convert a nondipping into a dipping 24-hour BP profile in some patients and cause some decrease in diurnal BP variability, but more data are necessary to explore these aspects better. CPAP treatment may also decrease BP reactivity to sleep apneas ${ }^{50}$ such that acute CPAP withdrawal does not immediately revert BP variability to the level observed before treatment initiation.

\section{Conclusion}

Current knowledge suggests that BP behavior in OSA plays a role in the increased cardiovascular risk that is typical of this disorder, not only through its high diurnal and even more its nocturnal BP values but also through the characteristics of its variability. In fact, high very short-term variability, nondipping BP profile and high MBPS, which are all common in OSA, are known risk factors.

Among the characteristics of BP variability in OSA, the most peculiar is the periodic recurrence of short BP peaks. However, this is not exclusive to OSA, as nocturnal BP peaks can be observed in other conditions with periodicity, in particular in patients with periodic leg movements. ${ }^{125}$ Sometimes, BP peaks reach very high levels. It is conceivable that a precise assessment of nocturnal BP that accurately takes into account values and duration of peaks carries prognostic 
Table 3 Changes in BP variability associated with CPAP treatment

\begin{tabular}{|c|c|c|c|}
\hline Methodology & Authors & Subjects, design & BP variability changes \\
\hline \multirow[t]{6}{*}{$\begin{array}{l}\text { Beat-by-beat BP } \\
\text { measurements }\end{array}$} & Ali et a ${ }^{39}$ & 8 OSA with and without CPAP & $\begin{array}{l}\text { In a } 30 \text {-minute period during sleep, lower coefficient of variation } \\
\text { of SBP and DBP with than without CPAP }\end{array}$ \\
\hline & Sforza et $\mathrm{al}^{46}$ & 25 OSA with and without CPAP & $\begin{array}{l}\text { During first night with CPAP, decreased coefficient of variation of } \\
\text { SBP and DBP in all sleep stages }\end{array}$ \\
\hline & Bonsignore et $\mathrm{al}^{116}$ & $\begin{array}{l}10 \text { normotensive OSA before OSA } \\
\text { treatment and after treatment } \\
\text { withdrawal }\end{array}$ & $\begin{array}{l}\text { In the first night of CPAP withdrawal after a } 5.5 \pm 3.7 \text {-month } \\
\text { treatment, lower SD of SBP and DBP during stage NREM2, but } \\
\text { not during waking, than before CPAP initiation }\end{array}$ \\
\hline & Marrone et $\mathrm{al}^{50}$ & $\begin{array}{l}13 \text { OSA under no pharmacological } \\
\text { therapy before OSA treatment and } \\
\text { after treatment withdrawal }\end{array}$ & $\begin{array}{l}\text { In apneic cycles during the first night of CPAP withdrawal after } \\
\text { a } 4.9 \pm 3.4-\text { month treatment, smaller SBP and DBP surges than in } \\
\text { apneic cycles occurring before CPAP initiation }\end{array}$ \\
\hline & Bonsignore et $\mathrm{al}^{1 / 4}$ & 18 OSA with and without CPAP & $\begin{array}{l}\text { In the first night with CPAP, decrease in SD of both SBP and DBP } \\
\text { in stages NREM } 2 \text { and REM, and decrease only in SD of DBP during } \\
\text { nocturnal waking }\end{array}$ \\
\hline & Carter et al ${ }^{115}$ & $\begin{array}{l}17 \text { OSA with OHS with and without } \\
\text { CPAP }\end{array}$ & $\begin{array}{l}\text { During the first night (titration) and after } 6 \text { weeks with CPAP, } \\
\text { similar reduction in the rate of nocturnal BP surges }\end{array}$ \\
\hline \multirow[t]{10}{*}{$\begin{array}{l}\text { ABPM } \\
\text { measurements }\end{array}$} & Pankow et al ${ }^{67}$ & 34 OSA with and without CPAP & $\begin{array}{l}\text { After 2-4 nights with CPAP, } 17 \text { of } 27 \text { who were nondippers at } \\
\text { baseline showed dipping }\end{array}$ \\
\hline & Engleman et al ${ }^{117}$ & $\begin{array}{l}\text { I3 OSA with placebo and CPAP } \\
\text { (crossover RCT) }\end{array}$ & $\begin{array}{l}\text { After } \geq 3 \text {-week treatment, nonsignificant change in prevalence of } \\
\text { nondipping BP pattern }\end{array}$ \\
\hline & Akashiba et al ${ }^{70}$ & 38 OSA without and with CPAP & $\begin{array}{l}15 \text { of } 22 \text { nondippers at baseline showed dipping at the third day of } \\
\text { CPAP therapy }\end{array}$ \\
\hline & Bao et $\mathrm{al}^{86}$ & $\begin{array}{l}\text { 4I OSA with placebo or CPAP } \\
\text { (parallel RCT) }\end{array}$ & $\begin{array}{l}\text { In patients receiving CPAP for either I or for } 7 \text { nights and in } \\
\text { patients receiving placebo, similar decrease in SD of SBP, DBP, and } \\
\text { MBP both during the day and during the night }\end{array}$ \\
\hline & Dursunoğlu et al ${ }^{118}$ & $\begin{array}{l}12 \text { OSA with and without auto- } \\
\text { CPAP }\end{array}$ & $\begin{array}{l}\text { The first day with autoadjusting CPAP, reduction in SD of SBP, } \\
\text { DBP and MBP at night, but not during the day }\end{array}$ \\
\hline & $\begin{array}{l}\text { Campos-Rodriguez } \\
\text { et al }{ }^{119}\end{array}$ & $\begin{array}{l}68 \text { hypertensive OSA with placebo } \\
\text { or CPAP (parallel RCT) }\end{array}$ & $\begin{array}{l}\text { After a 4-week treatment, proportion of patients turning BP } \\
\text { pattern from nondipper to dipper not significantly different } \\
\text { between placebo and CPAP }\end{array}$ \\
\hline & Wang et $\mathrm{al}^{120}$ & $\begin{array}{l}60 \text { mild OSA and } 48 \text { moderate- } \\
\text { severe OSA with hypertension with } \\
\text { and without CPAP }\end{array}$ & $\begin{array}{l}\text { After 3-month CPAP or surgery, } 23 \text { of } 31 \text { mild OSA and } 19 \text { of } \\
28 \text { moderate-severe OSA patients turned from nondippers to } \\
\text { dippers }\end{array}$ \\
\hline & $\begin{array}{l}\text { Martínez-García } \\
\text { et al }{ }^{121}\end{array}$ & $\begin{array}{l}194 \text { OSA with resistant hypertension } \\
\text { with and without CPAP (parallel } \\
\text { RCT) }\end{array}$ & $\begin{array}{l}\text { After } 12 \text { weeks, fewer patients treated by CPAP than controls } \\
\text { showed nondipper or riser profiles }\end{array}$ \\
\hline & Muxfeldt et al ${ }^{122}$ & $\begin{array}{l}117 \text { moderate-severe OSA with } \\
\text { resistant hypertension with placebo } \\
\text { or CPAP (parallel RCT) }\end{array}$ & $\begin{array}{l}\text { After } 6 \text { months, NS difference between CPAP and placebo } \\
\text { treatment in prevalence of nondipping and riser BP patterns }\end{array}$ \\
\hline & Lemmer et $\mathrm{al}^{123}$ & 17 OSA with and without CPAP & $\begin{array}{l}5 \text { of } 14 \text { nondippers at baseline showed dipping after } 8 \text { weeks with } \\
\text { CPAP }\end{array}$ \\
\hline \multirow[t]{2}{*}{$\begin{array}{l}\text { Office or home } \\
\text { BP measurements }\end{array}$} & Pengo et $\mathrm{al}^{124}$ & $\begin{array}{l}78 \text { OSA with and without auto- } \\
\text { CPAP }\end{array}$ & $\begin{array}{l}\text { After a 3-week autoadjusting CPAP therapy, decrease in SD of } \\
\text { three repeated waking SBP but not DBP measurements }\end{array}$ \\
\hline & Lettau et $\mathrm{al}^{92}$ & $\begin{array}{l}\text { I75 OSA continuing or withdrawing } \\
\text { CPAP (parallel RCT) }\end{array}$ & $\begin{array}{l}\text { After a 2-week CPAP withdrawal, increased SD of three } \\
\text { consecutive office morning SBP but not of DBP measurements; in } \\
\text { the same period, no effect on day-to-day BP variability }\end{array}$ \\
\hline
\end{tabular}

Abbreviations: ABPM, ambulatory blood pressure monitoring; CPAP, continuous positive airway pressure; DBP, diastolic BP; MBP, mean BP; NREM, non-rapid eye movement; OSA, obstructive sleep apnea; RCT, randomized controlled trial; SBP, systolic BP.

significance. In fact, it has been found that maximum BP values measured over several days may be better related to several cardiovascular outcomes than mean values. ${ }^{126}$ Today, a precise detection of hypertensive peaks is not easy in common clinical practice. Research of new monitoring systems is in progress. The new techniques appear promising, ${ }^{56,57}$ although they still need to be better validated and probably refined.
Once BP variability is evaluated, effective strategies should be applied to improve it. BP variability may be reduced with treatment of disordered breathing events or with a pharmacological treatment directly addressing BP. As described earlier, many studies have observed a reduction in BP variability and an improvement of BP profile with CPAP treatment, but not all findings have been in agreement. It is 
unknown whether differing interindividual effects of CPAP on BP variability contribute to the variable efficacy of CPAP. Knowledge on pharmacological treatment of hypertension to be preferentially used in OSA is still limited, ${ }^{127,128}$ and the few available data on chronotherapy for hypertension in OSA are inconsistent. Besides, more experience is required with regard to combined effects of treatment of OSA by CPAP, weight loss, or other treatments and antihypertensive pharmacological therapy.

Today, although OSA is believed to increase cardiovascular risk, cardiovascular benefits of OSA treatment are questioned, based on the results of randomized controlled trials. ${ }^{129}$ Research is on the way for a personalized approach to the treatment of several diseases, including OSA. ${ }^{130}$ Individual characteristics of BP variability could be one factor to take into consideration in the management of OSA patients and in the choice of a specific therapeutic approach to reduce the cardiovascular burden of the disease.

\section{Disclosure}

The authors report no conflicts of interest in this work.

\section{References}

1. Javaheri S, Barbe F, Campos-Rodriguez F, et al. Sleep apnea: types, mechanisms, and clinical cardiovascular consequences. J Am Coll Cardiol. 2017;69(7):841-858.

2. Parati G, Ochoa JE, Lombardi C, Bilo G. Assessment and management of blood-pressure variability. Nat Rev Cardiol. 2013;10(3): $143-155$.

3. Stevens SL, Wood S, Koshiaris C, et al. Blood pressure variability and cardiovascular disease: systematic review and meta-analysis. $B M J$. 2016;354:i4098.

4. Stergiou GS, Parati G. How to best assess blood pressure? The ongoing debate on the clinical value of blood pressure average and variability. Hypertension. 2011;57(6):1041-1042.

5. Taylor KS, Heneghan CJ, Stevens RJ, Adams EC, Nunan D, Ward A. Heterogeneity of prognostic studies of 24-hour blood pressure variability: systematic review and meta-analysis. PLoS One. 2015;10(5):e0126375.

6. Portaluppi F, Tiseo R, Smolensky MH, Hermida RC, Ayala DE, Fabbian F. Circadian rhythms and cardiovascular health. Sleep Med Rev. 2012;16(2):151-166.

7. Smolensky MH, Hermida RC, Portaluppi F. Circadian mechanisms of 24-hour blood pressure regulation and patterning. Sleep Med Rev. 2017;33:4-16.

8. Murali NS, Svatikova A, Somers VK. Cardiovascular physiology and sleep. Front Biosci. 2003;8:s636-s652.

9. Imholz BP, Wieling W, van Montfrans GA, Wesseling KH. Fifteen years experience with finger arterial pressure monitoring: assessment of the technology. Cardiovasc Res. 1998;38(3):605-616.

10. Maggi R, Viscardi V, Furukawa T, Brignole M. Non-invasive continuous blood pressure monitoring of tachycardic episodes during interventional electrophysiology. Europace. 2010;12(11): 1616-1622.

11. Dueck R, Goedje O, Clopton P. Noninvasive continuous beat-to-beat radial artery pressure via TL-200 applanation tonometry. J Clin Monit Comput. 2012;26(2):75-83.
12. Whelton PK, Carey RM, Aronow WS, et al. 2017 ACC/AHA/AAPA/ ABC/ACPM/AGS/APhA/ASH/ASPC/NMA/PCNA guideline for the prevention, detection, evaluation, and management of high blood pressure in adults: a report of the American College of Cardiology/ American Heart Association task force on clinical practice guidelines. Hypertension. 2018;71(6):1269-1324.

13. Goldstein DS, Cheshire WP Jr. Beat-to-beat blood pressure and heart rate responses to the Valsalva maneuver. Clin Auton Res. 2017;27(6):361-367.

14. Pinna GD, Maestri R, la Rovere MT. Assessment of baroreflex sensitivity from spontaneous oscillations of blood pressure and heart rate: proven clinical value? Physiol Meas. 2015;36(4):741-753.

15. Morgan BJ, Crabtree DC, Puleo DS, Badr MS, Toiber F, Skatrud JB. Neurocirculatory consequences of abrupt change in sleep state in humans. J Appl Physiol (1985). 1996;80(5):1627-1636.

16. Hansen TW, Li Y, Boggia J, Thijs L, Richart T, Staessen JA. Predictive role of the nighttime blood pressure. Hypertension. 2011;57(1):3-10.

17. Asayama K, Schutte R, LiY, Hansen TW, Staessen JA. Blood pressure variability in risk stratification: what does it add? Clin Exp Pharmacol Physiol. 2014;41:1-8.

18. Fagard RH, Celis H, Thijs L, et al. Daytime and nighttime blood pressure as predictors of death and cause-specific cardiovascular events in hypertension. Hypertension. 2008;51(1):55-61.

19. Yano Y, Kario K. Nocturnal blood pressure and cardiovascular disease: a review of recent advances. Hypertens Res. 2012;35(7):695-701.

20. Cuspidi C, Sala C, Valerio C, Negri F, Mancia G. Nocturnal hypertension and organ damage in dippers and nondippers. Am J Hypertens. 2012;25(8):869-875

21. Mancia G, Fagard R, Narkiewicz K, et al. 2013 ESH/ESC guidelines for the management of arterial hypertension: the task force for the management of arterial hypertension of the European Society of Hypertension (ESH) and of the European Society of Cardiology (ESC). J Hypertens. 2013;31(7):1281-1357.

22. Aparicio LS, Barochiner J, Cuffaro PE, et al. Determinants of the morning-evening home blood pressure difference in treated hypertensives: the HIBA-Home Study. Int J Hypertens. 2014;2014:569259.

23. Kario K, Saito I, Kushiro T, et al. Morning home blood pressure is a strong predictor of coronary artery disease: the HONEST study. $J \mathrm{Am}$ Coll Cardiol. 2016;67(13):1519-1527.

24. Matsui Y, Eguchi K, Shibasaki S, et al. Association between the morning-evening difference in home blood pressure and cardiac damage in untreated hypertensive patients. J Hypertens. 2009;27(4):712-720.

25. O'Brien E, Parati G, Stergiou G. Ambulatory blood pressure measurement: what is the international consensus? Hypertension. 2013;62(6):988-994.

26. Crespo C, Fernández JR, Aboy M, Mojón A. Clinical application of a novel automatic algorithm for actigraphy-based activity and rest period identification to accurately determine awake and asleep ambulatory blood pressure parameters and cardiovascular risk. Chronobiol Int. 2013;30(1-2):43-54.

27. Salles GF, Reboldi G, Fagard RH, et al. Prognostic effect of the nocturnal blood pressure fall in hypertensive patients: the Ambulatory Blood Pressure Collaboration in Patients with Hypertension (ABC-H) meta-analysis. Hypertension. 2016;67(4):693-700.

28. Kario K. Prognosis in relation to blood pressure variability: pro side of the argument. Hypertension. 2015;65(6):1163-1169.

29. Kario K, Pickering TG, Umeda Y, et al. Morning surge in blood pressure as a predictor of silent and clinical cerebrovascular disease in elderly hypertensives: a prospective study. Circulation. 2003;107(10):1401-1406.

30. Li Y, Thijs L, Hansen TW, et al. Prognostic value of the morning blood pressure surge in 5645 subjects from 8 populations. Hypertension. 2010;55(4):1040-1048.

31. Pierdomenico SD, Pierdomenico AM, Coccina F, Lapenna D, Porreca E. Prognostic value of nondipping and morning surge in elderly treated hypertensive patients with controlled ambulatory blood pressure. $\mathrm{Am}$ J Hypertens. 2017;30(2):159-165. 
32. Israel S, Israel A, Ben-Dov IZ, Bursztyn M. The morning blood pressure surge and all-cause mortality in patients referred for ambulatory blood pressure monitoring. Am J Hypertens. 2011;24(7):796-801.

33. Verdecchia P, Angeli F, Mazzotta G, et al. Day-night dip and earlymorning surge in blood pressure in hypertension: prognostic implications. Hypertension. 2012;60(1):34-42.

34. Bombelli M, Fodri D, Toso E, et al. Relationship among morning blood pressure surge, 24-hour blood pressure variability, and cardiovascular outcomes in a white population. Hypertension. 2014;64(5):943-950.

35. Kario K. Time for focus on morning hypertension: pitfall of current antihypertensive medication. Am J Hypertens. 2005;18(2 Pt 1): 149-151.

36. Sawatari H, Chishaki A, Ando SI. The epidemiology of sleep disordered breathing and hypertension in various populations. Curr Hypertens Rev. 2016;12(1):12-17.

37. Marrone O, Riccobono L, Salvaggio A, Mirabella A, Bonanno A, Bonsignore MR. Catecholamines and blood pressure in obstructive sleep apnea syndrome. Chest. 1993;103(3):722-777.

38. Shiomi T, Guilleminault C, Stoohs R, Schnittger I. Leftward shift of the interventricular septum and pulsus paradoxus in obstructive sleep apnea syndrome. Chest. 1991;100(4):894-902.

39. Ali NJ, Davies RJ, Fleetham JA, Stradling JR. The acute effects of continuous positive airway pressure and oxygen administration on blood pressure during obstructive sleep apnea. Chest. 1992;101(6):1526-1532.

40. Coccagna G, Mantovani M, Brignani F, Parchi C, Lugaresi E. Continuous recording of the pulmonary and systemic arterial pressure during sleep in syndromes of hypersomnia with periodic breathing. Bull Physiopathol Respir (Nancy). 1972;8(5):1159-1172.

41. Tun Y, Okabe S, Hida W, et al. Nocturnal blood pressure during apnoeic and ventilatory periods in patients with obstructive sleep apnoea. Eur Respir J. 1999;14(6):1271-1277.

42. Lofaso F, Goldenberg F, d'Ortho MP, Coste A, Harf A. Arterial blood pressure response to transient arousals from NREM sleep in nonapneic snorers with sleep fragmentation. Chest. 1998;113(4):985-991.

43. Planès C, Leroy M, Fayet G, Aegerter P, Foucher A, Raffestin B. Exacerbation of sleep-apnoea related nocturnal blood-pressure fluctuations in hypertensive subjects. Eur Respir J. 2002;20(1):151-157.

44. Ratnavadivel R, Chau N, Stadler D, Yeo A, McEvoy RD, Catcheside PG. Marked reduction in obstructive sleep apnea severity in slow wave sleep. J Clin Sleep Med. 2009;5(6):519-524.

45. Findley LJ, Wilhoit SC, Suratt PM. Apnea duration and hypoxemia during REM sleep in patients with obstructive sleep apnea. Chest. 1985;87(4):432-436.

46. Sforza E, Capecchi V, Lugaresi E. Haemodynamic effects of shortterm nasal continuous positive airway pressure therapy in sleep apnoea syndrome: monitoring by a finger arterial pressure device. Eur Respir J. 1992;5(7):858-863.

47. Davies RJ, Crosby J, Vardi-Visy K, Clarke M, Stradling JR. Noninvasive beat to beat arterial blood pressure during non-REM sleep in obstructive sleep apnoea and snoring. Thorax. 1994;49(4):335-339.

48. Sforza E, Lugaresi E. Determinants of the awakening rise in systemic blood pressure in obstructive sleep apnea syndrome. Blood Press. 1995;4(4):218-225.

49. Leroy M, van Surell C, Pilliere R, et al. Short-term variability of blood pressure during sleep in snorers with or without apnea. Hypertension. 1996;28(6):937-943.

50. Marrone O, Salvaggio A, Bonsignore MR, Insalaco G, Bonsignore G. Blood pressure responsiveness to obstructive events during sleep after chronic CPAP. Eur Respir J. 2003;21(3):509-514.

51. Grote L, Heitmann J, Köhler U, Penzel T, Peter JH, Wichert P. Assessment of the nocturnal blood pressure relative to sleep stages in patients with obstructive sleep apnea. Z Kardiol. 1996;85 Suppl 3:112-114.

52. Narkiewicz K, Montano N, Cogliati C, van de Borne PJ, Dyken ME, Somers VK. Altered cardiovascular variability in obstructive sleep apnea. Circulation. 1998;98(11):1071-1077.
53. Marrone O, Romano S, Insalaco G, Bonsignore MR, Salvaggio A, Bonsignore $G$. Influence of sampling interval on the evaluation of nocturnal blood pressure in subjects with and without obstructive sleep apnoea. Eur Respir J. 2000;16(4):653-658.

54. Davies RJ, Jenkins NE, Stradling JR. Effect of measuring ambulatory blood pressure on sleep and on blood pressure during sleep. $B M J$. 1994;308(6932):820-823.

55. Heude E, Bourgin P, Feigel P, Escourrou P. Ambulatory monitoring of blood pressure disturbs sleep and raises systolic pressure at night in patients suspected of suffering from sleep-disordered breathing. Clin Sci (Lond). 1996;91(1):45-50.

56. Shirasaki O, Kuwabara M, Saito M, Tagami K, Washiya S, Kario K. Development and clinical application of a new technique for detecting 'sleep blood pressure surges' in sleep apnea patients based on a variable desaturation threshold. Hypertens Res. 2011;34(8):922-928.

57. Kuwabara M, Hamasaki H, Tomitani N, Shiga T, Kario K. Novel triggered nocturnal blood pressure monitoring for sleep apnea syndrome: distribution and reproducibility of hypoxia-triggered nocturnal blood pressure measurements. J Clin Hypertens (Greenwich). 2017;19(1):30-37.

58. Hoffstein V, Mateika J. Evening-to-morning blood pressure variations in snoring patients with and without obstructive sleep apnea. Chest. 1992;101(2):379-384.

59. Stradling JR, Barbour C, Glennon J, Langford BA, Crosby JH. Which aspects of breathing during sleep influence the overnight fall of blood pressure in a community population? Thorax. 2000;55(5):393-398.

60. Wang Y, Yang Q, Feng J, Cao J, Chen B. The prevalence and clinical features of hypertension in patients with obstructive sleep apnea hypopnea syndrome and related nursing strategies. J Nurs Res. 2016;24(1):41-47.

61. Lavie-Nevo K, Pillar G. Evening-morning differences in blood pressure in sleep apnea syndrome: effect of gender. Am J Hypertens. 2006;19(10):1064-1069.

62. Mokros Ł, Kuczyński W, Franczak Ł, Białasiewicz P. Morning diastolic blood pressure may be independently associated with severity of obstructive sleep apnea in non-hypertensive patients: a cross-sectional study. J Clin Sleep Med. 2017;13(7):905-910.

63. Ting H, Lo HS, Chang SY, et al. Post- to pre-overnight sleep systolic blood pressures are associated with sleep respiratory disturbance, pro-inflammatory state and metabolic situation in patients with sleepdisordered breathing. Sleep Med. 2009;10(7):720-725.

64. Huang YC, Lin CY, Lan CC, et al. Comparison of cardiovascular co-morbidities and CPAP use in patients with positional and nonpositional mild obstructive sleep apnea. BMC Pulm Med. 2014;14:153.

65. McGinty D, Beahm E, Stern N, Littner M, Sowers J, Reige W. Nocturnal hypotension in older men with sleep-related breathing disorders. Chest. 1988;94(2):305-311.

66. Wilcox I, Grunstein RR, Collins FL, Doyle JM, Kelly DT, Sullivan CE. Circadian rhythm of blood pressure in patients with obstructive sleep apnea. Blood Press. 1992;1(4):219-222.

67. Pankow W, Nabe B, Lies A, Kohl FV, Lohmann FW. Influence of obstructive sleep apnoea on circadian blood pressure profile. J Sleep Res. 1995;4 Suppl 1:102-106.

68. Nabe B, Lies A, Pankow W, Kohl FV, Lohmann FW. Determinants of circadian blood pressure rhythm and blood pressure variability in obstructive sleep apnoea. J Sleep Res. 1995;4 Suppl 1:97-101.

69. Suzuki M, Guilleminault C, Otsuka K, Shiomi T. Blood pressure "dipping" and "non-dipping" in obstructive sleep apnea syndrome patients. Sleep. 1996;19(5):382-387.

70. Akashiba T, Minemura H, Yamamoto H, Kosaka N, Saito O, Horie T. Nasal continuous positive airway pressure changes blood pressure "non-dippers" to "dippers" in patients with obstructive sleep apnea. Sleep. 1999;22(7):849-853.

71. Loredo JS, Ancoli-Israel S, Dimsdale JE. Sleep quality and blood pressure dipping in obstructive sleep apnea. Am J Hypertens. 2001;14(9 Pt 1): $887-892$. 
72. MaY, Sun S, Peng CK, Fang Y, Thomas RJ. Ambulatory blood pressure monitoring in Chinese patients with obstructive sleep apnea. J Clin Sleep Med. 2017;13(3):433-439.

73. Baguet JP, Boutin I, Barone-Rochette G, et al. Hypertension diagnosis in obstructive sleep apnea: self or 24-hour ambulatory blood pressure monitoring? Int J Cardiol. 2013;167(5):2346-2347.

74. Baguet JP, Lévy P, Barone-Rochette G, et al. Masked hypertension in obstructive sleep apnea syndrome. J Hypertens. 2008;26(5):885-892.

75. Drager LF, Diegues-Silva L, Diniz PM, et al. Obstructive sleep apnea, masked hypertension, and arterial stiffness in men. Am J Hypertens. 2010;23(3):249-254

76. Noda A, Okada T, Hayashi H, Yasuma F, Yokota M. 24-Hour ambulatory blood pressure variability in obstructive sleep apnea syndrome. Chest. 1993;103(5):1343-1347.

77. Nagata K, Osada N, Shimazaki M, et al. Diurnal blood pressure variation in patients with sleep apnea syndrome. Hypertens Res. 2008;31(2):185-191.

78. Sasaki N, Ozono R, Yamauchi R, et al. The relationship between morning hypertension and sleep quality in patients with obstructive sleep apnea syndrome. Clin Exp Hypertens. 2013;35(4):250-256.

79. Cho JS, Ihm SH, Kim CJ, et al. Obstructive sleep apnea using WatchPat 200 is independently associated with an increase in morning blood pressure surge in never-treated hypertensive patients. J Clin Hypertens (Greenwich). 2015;17(9):675-681.

80. Seif F, Patel SR, Walia HK, et al. Obstructive sleep apnea and diurnal nondipping hemodynamic indices in patients at increased cardiovascular risk. J Hypertens. 2014;32(2):267-275.

81. Noda A, Yasuma F, Okada T, Yokota M. Influence of movement arousal on circadian rhythm of blood pressure in obstructive sleep apnea syndrome. J Hypertens. 2000;18(5):539-544.

82. Sasaki N, Ozono R, Yamauchi R, et al. Age-related differences in the mechanism of nondipping among patients with obstructive sleep apnea syndrome. Clin Exp Hypertens. 2012;34(4):270-277.

83. Li X, Li J, Liu K, et al. Association between sleep disorders and morning blood pressure in hypertensive patients. Clin Exp Hypertens. 2018;40(4):337-343.

84. Hla KM, Young T, Finn L, Peppard PE, Szklo-Coxe M, Stubbs M. Longitudinal association of sleep-disordered breathing and nondipping of nocturnal blood pressure in the Wisconsin Sleep Cohort study Sleep. 2008;31(6):795-800.

85. Mokhlesi B, Hagen EW, Finn LA, Hla KM, Carter JR, Peppard PE. Obstructive sleep apnoea during REM sleep and incident non-dipping of nocturnal blood pressure: a longitudinal analysis of the Wisconsin Sleep Cohort. Thorax. 2015;70(11):1062-1069.

86. Bao X, Nelesen RA, Loredo JS, Dimsdale JE, Ziegler MG. Blood pressure variability in obstructive sleep apnea: role of sympathetic nervous activity and effect of continuous positive airway pressure. Blood Press Monit. 2002;7(6):301-307.

87. Steinhorst AP, Gonçalves SC, Oliveira AT, et al. Influence of sleep apnea severity on blood pressure variability of patients with hypertension. Sleep Breath. 2014;18(2):397-401.

88. Ke X, Sun Y, Yang R, et al. Association of 24 h-systolic blood pressure variability and cardiovascular disease in patients with obstructive sleep apnea. BMC Cardiovasc Disord. 2017;17:287.

89. Shi J, Piao J, Liu B, et al. Obstructive sleep apnea increases systolic and diastolic blood pressure variability in hypertensive patients. Blood Press Monit. 2017;22(4):208-212.

90. Shao L, Heizhati M, Yao X, et al. Influences of obstructive sleep apnea on blood pressure variability might not be limited only nocturnally in middle-aged hypertensive males. Sleep Breath. 2018;22(2): 377-384.

91. Martynowicz H, Porębska I, Poręba R, Mazur G, Brzecka A. Nocturnal blood pressure variability in patients with obstructive sleep apnea syndrome. Adv Exp Med Biol. 2016;952:9-15.

92. Lettau F, Schwarz EI, Stradling JR, Kohler M. Blood pressure variability in obstructive sleep apnoea: data from 4 randomised controlled CPAP withdrawal trials. Respiration. 2017;93(5):311-318.
93. Ulasli SS, Sarıaydın M, Gunay E, et al. Effects of nondipping pattern on systemic inflammation in obstructive sleep apnea. Sleep Breath. 2015;19(4):1185-1190.

94. Ishikawa J, Hoshide S, Eguchi K, et al. Increased low-grade inflammation and plasminogen-activator inhibitor-1 level in nondippers with sleep apnea syndrome. J Hypertens. 2008;26(6):1181-1187.

95. Lee S, Thomas RJ, Kim H, et al. Association between high nocturnal blood pressure and white matter change and its interaction by obstructive sleep apnoea among normotensive adults. J Hypertens. 2014;32(10):2005-2012.

96. Sasaki N, Ozono R, Edahiro Y, et al. Impact of non-dipping on cardiovascular outcomes in patients with obstructive sleep apnea syndrome. Clin Exp Hypertens. 2015;37(6):449-453.

97. Gami AS, Howard DE, Olson EJ, Somers VK. Day-night pattern of sudden death in obstructive sleep apnea. $N$ Engl J Med. 2005;352(12):1206-1214.

98. Martins EF, Martinez D, da Silva FA, et al. Disrupted day-night pattern of cardiovascular death in obstructive sleep apnea. Sleep Med. 2017;38:144-150.

99. Kuniyoshi FH, Garcia-Touchard A, Gami AS, et al. Day-night variation of acute myocardial infarction in obstructive sleep apnea. J Am Coll Cardiol. 2008;52(5):343-346.

100. Ishibashi Y, Osada N, Sekiduka H, et al. Peak time of acute coronary syndrome in patients with sleep disordered breathing. J Cardiol. 2009;53(2):164-170.

101. García MA, Blancart RG, Salt LC, Cataluña JJ, Escamilla T, Sánchez PR. Prevalencia de trastornos respiratorios durante el sueño en pacientes con ictus isquémico agudo: influencia del momento de aparición del ictus [Prevalence of sleep-disordered breathing in patients with acute ischemic stroke: influence of onset time of stroke]. Arch Bronconeumol. 2004;40(5):196-202.

102. Hsieh SW, Lai CL, Liu CK, Hsieh CF, Hsu CY. Obstructive sleep apnea linked to wake-up strokes. J Neurol. 2012;259(7):1433-1439.

103. Weaver TE, Maislin G, Dinges DF, et al. Relationship between hours of CPAP use and achieving normal levels of sleepiness and daily functioning. Sleep. 2007;30(6):711-719.

104. Hermida RC, Ayala DE, Smolensky MH, Fernández JR, Mojón A, Portaluppi F. Sleep-time blood pressure: unique sensitive prognostic marker of vascular risk and therapeutic target for prevention. Sleep Med Rev. 2017;33:17-27.

105. Fava C, Dorigoni S, Vedove FD, et al. Effect of CPAP on blood pressure in patients with OSA/hypopnea a systematic review and meta-analysis. Chest. 2014;145(4):762-771.

106. Schein AS, Kerkhoff AC, Coronel CC, Plentz RD, Sbruzzi G. Continuous positive airway pressure reduces blood pressure in patients with obstructive sleep apnea: a systematic review and meta-analysis with 1000 patients. J Hypertens. 2014;32(9):1762-1773.

107. Hu X, Fan J, Chen S, Yin Y, Zrenner B. The role of continuous positive airway pressure in blood pressure control for patients with obstructive sleep apnea and hypertension: a meta-analysis of randomized controlled trials. J Clin Hypertens (Greenwich). 2015;17(3):215-222.

108. Sun Y, Huang ZY, Sun QR, Qiu LP, Zhou TT, Zhou GH. CPAP therapy reduces blood pressure for patients with obstructive sleep apnoea: an update meta-analysis of randomized clinical trials. Acta Cardiol. 2016;71(3):275-280.

109. Pépin JL, Tamisier R, Barone-Rochette G, Launois SH, Lévy P, Baguet JP. Comparison of continuous positive airway pressure and valsartan in hypertensive patients with sleep apnea. Am J Respir Crit Care Med. 2010;182(7):954-960.

110. Serinel Y, Yee BJ, Grunstein RR, et al. Chronotherapy for hypertension in obstructive sleep apnoea (CHOSA): a randomised, double-blind, placebo-controlled crossover trial. Thorax. 2017;72(6):550-558.

111. Kario K, Kuwabara M, Hoshide S, Nagai M, Shimpo M. Effects of nighttime single-dose administration of vasodilating vs sympatholytic antihypertensive agents on sleep blood pressure in hypertensive patients with sleep apnea syndrome. J Clin Hypertens (Greenwich). 2014;16(6):459-466. 
112. Yoshida T, Kuwabara M, Hoshide S, Kario K. The effect of the bedtimedosing doxazosin on nocturnal hypoxia-triggered blood pressure surge in a young adult man with severe obstructive sleep apnea syndrome and a history of three recurrent sleep-onset strokes. Blood Press Monit. 2017;22(3):173-174.

113. Kasiakogias A, Tsioufis C, Thomopoulos C, et al. Evening versus morning dosing of antihypertensive drugs in hypertensive patients with sleep apnoea: a cross-over study. J Hypertens. 2015;33(2): 393-400.

114. Bonsignore MR, Parati G, Insalaco G, et al. Baroreflex control of heart rate during sleep in severe obstructive sleep apnoea: effects of acute CPAP. Eur Respir J. 2006;27(1):128-135.

115. Carter JR, Fonkoue IT, Grimaldi D, et al. Positive airway pressure improves nocturnal beat-to-beat blood pressure surges in obesity hypoventilation syndrome with obstructive sleep apnea. Am J Physiol Regul Integr Comp Physiol. 2016;310(7):R602-R611.

116. Bonsignore MR, Parati G, Insalaco G, et al. Continuous positive airway pressure treatment improves baroreflex control of heart rate during sleep in severe obstructive sleep apnea syndrome. Am J Respir Crit Care Med. 2002;166(3):279-286.

117. Engleman HM, Gough K, Martin SE, Kingshott RN, Padfield PL, Douglas NJ. Ambulatory blood pressure on and off continuous positive airway pressure therapy for the sleep apnea/hypopnea syndrome: effects in "non-dippers". Sleep. 1996;19(5):378-381.

118. Dursunoğlu N, Dursunoğlu D, Cuhadaroğlu C, Kiliçaslan Z. Acute effects of automated continuous positive airway pressure on blood pressure in patients with sleep apnea and hypertension. Respiration. 2005;72(2):150-155.

119. Campos-Rodriguez F, Grilo-Reina A, Perez-Ronchel J, et al. Effect of continuous positive airway pressure on ambulatory BP in patients with sleep apnea and hypertension: a placebo-controlled trial. Chest. 2006;129(6):1459-1467.

120. Wang HL, Wang Y, Zhang Y, et al. Changes in plasma angiotensin II and circadian rhythm of blood pressure in hypertensive patients with sleep apnea syndrome before and after treatment. Chin Med Sci J. 2011;26(1):9-13.
121. Martínez-García MA, Capote F, Campos-Rodríguez F, et al. Effect of CPAP on blood pressure in patients with obstructive sleep apnea and resistant hypertension: the HIPARCO randomized clinical trial. JAMA. 2013;310(22):2407-2415.

122. Muxfeldt ES, Margallo V, Costa LM, et al. Effects of continuous positive airway pressure treatment on clinic and ambulatory blood pressures in patients with obstructive sleep apnea and resistant hypertension: a randomized controlled trial. Hypertension. 2015;65(4):736-742.

123. Lemmer B, Scholtze J, Schmitt J. Circadian rhythms in blood pressure, heart rate, hormones, and on polysomnographic parameters in severe obstructive sleep apnea syndrome patients: effect of continuous positive airway pressure. Blood Press Monit. 2016;21(3):136-143.

124. Pengo MF, Ratneswaran C, Berry M, et al. Effect of continuous positive airway pressure on blood pressure variability in patients with obstructive sleep apnea. J Clin Hypertens (Greenwich). 2016;18(11):1180-1184.

125. Pennestri MH, Montplaisir J, Fradette L, Lavigne G, Colombo $\mathrm{R}$, Lanfranchi PA. Blood pressure changes associated with periodic leg movements during sleep in healthy subjects. Sleep Med. 2013;14(6):555-561.

126. Matsui Y, Ishikawa J, Eguchi K, Shibasaki S, Shimada K, Kario K. Maximum value of home blood pressure: a novel indicator of target organ damage in hypertension. Hypertension. 2011;57(6):1087-1093.

127. Kario K. Obstructive sleep apnea syndrome and hypertension: mechanism of the linkage and 24-h blood pressure control. Hypertens Res. 2009;32(7):537-541.

128. Parati G, Lombardi C, Hedner J, et al. Recommendations for the management of patients with obstructive sleep apnoea and hypertension. Eur Respir J. 2013;41(3):523-538.

129. Abuzaid AS, al Ashry HS, Elbadawi A, et al. Meta-analysis of cardiovascular outcomes with continuous positive airway pressure therapy in patients with obstructive sleep apnea. Am J Cardiol. 2017;120(4):693-699.

130. Bonsignore MR, Giron MC, Marrone O, Castrogiovanni A, Montserrat JM. Personalised medicine in sleep respiratory disorders: focus on obstructive sleep apnoea diagnosis and treatment. Eur Respir Rev. 2017;26:170069.
Nature and Science of Sleep

\section{Publish your work in this journal}

Nature and Science of Sleep is an international, peer-reviewed, open access journal covering all aspects of sleep science and sleep medicine, including the neurophysiology and functions of sleep, the genetics of sleep, sleep and society, biological rhythms, dreaming, sleep disorders and therapy, and strategies to optimize healthy sleep. The manuscript

\section{Dovepress}

management system is completely online and includes a very quick and fair peer-review system, which is all easy to use. Visit http://www. dovepress.com/testimonials.php to read real quotes from published authors. 